\title{
Nitrotyrosine and Nitrate/Nitrite Levels in Cardiac Arrest Survivors Treated With Endovascular Hypothermia
}

\author{
A. KRÜGER ${ }^{1}$, P. OŠŤÁDAL ${ }^{1}$, D. VONDRÁKOVÁ ${ }^{1}$, M. JANOTKA ${ }^{1}$, J. HERGET ${ }^{2}$ \\ ${ }^{1}$ Cardiovascular Center, Department of Cardiology, Na Homolce Hospital, Prague, Czech Republic, \\ ${ }^{2}$ Department of Physiology, Second Faculty of Medicine, Charles University, Prague, Czech \\ Republic
}

Received December 22, 2011

Accepted May 3, 2012

On-line June 6, 2012

\section{Summary}

The protective effect of therapeutic hypothermia in cardiac arrest survivors (CAS) has been previously well documented. Animal studies have indicated that attenuation of tissue oxidative stress (OS) may be involved in the mechanisms that lead to the beneficial effect of hypothermia. The extent of OS and nitric oxide (NO) production in adult CAS treated with endovascular hypothermia is, however, unknown. A total of 11 adult patients who experienced cardiac arrest out of hospital were included in the present study, and all were treated with mild hypothermia using the Thermogard XP (Alsius, USA) endovascular system. A target core temperature of $33^{\circ} \mathrm{C}$ was maintained for 24 hours, with a subsequent rewarming rate of $0.15{ }^{\circ} \mathrm{C}$ per hour, followed by normothermia at $36.8^{\circ} \mathrm{C}$. Blood samples for the measurement of nitrotyrosine and nitrate/nitrite levels were drawn at admission and every 6 hours thereafter for two days. During the hypothermic period, the levels of nitrotyrosine and nitrates/nitrites were comparable with baseline values. During the rewarming period, serum levels of both parameters gradually increased and, during the normothermic period, the levels were significantly higher compared with hypothermic levels (nitrotyrosine, $\mathrm{P}<0.001$; nitrates/nitrites, $\mathrm{P}<0.05$ ). In our study, significantly lower levels of nitrotyrosine and nitrates/nitrites were demonstrated during hypothermia compared with levels during the normothermic period in adult CAS. These data suggest that attenuation of OS and NO production may be involved in the protective effect of hypothermia in adult CAS.

\section{Key words}

Cardiac arrest • Hypothermia • Nitrotyrosine • Nitrates/nitrites • Oxidative stress

\section{Corresponding author}

P. Oštádal, Cardiovascular Center, Department of Cardiology, Na Homolce Hospital, 15030, Prague, Czech Republic. Fax: +420257272974. E-mail: ostadal@yahoo.com

Cardiopulmonary resuscitation is an essential, life-saving procedure. However, global ischemia during cardiac arrest induces the activation of several pathogenic pathways that potentially lead to fatal damage (i.e., ischemia-reperfusion injury). This complex process is generally known as post-cardiac arrest syndrome (PCAS). The clinical impact of PCAS depends on various factors, particularly on the duration of global ischemia, comorbidities and the patient's condition before the cardiac arrest. Management of PCAS is based on the therapy used to treat the primary disease (e.g., myocardial infarction) and the prevention of the recurrence of circulation arrest, with the ultimate goals of hemodynamic stabilization and neuroprotection (Neumar et al. 2008, Nolan et al. 2008).

Many pathogenic mechanisms are involved in the development of PCAS, with oxidative stress (OS) likely playing an important role. OS is characterized by excessive production of reactive oxygen and nitrogen species (e.g., superoxide, hydrogen peroxide, hydroxyl radical, nitric oxide and peroxynitrite) (Dhalla et al. 
2000b). These very unstable molecules are produced during and after patient resuscitation and can react directly with important cellular structures or form other reactive products. OS results in damage to cellular membranes, mitochondria, endoplasmic reticulum and/or nuclear DNA. Under physiological conditions, the harmful effects of reactive oxygen and nitrogen species are usually prevented by the body's antioxidant defence systems (i.e., superoxide dismutase, catalase, glutathione peroxidase). However, antioxidant capacity to provide protection is insufficient during ischemia-reperfusion and does not effectively protect against cell damage (Dhalla et al. 2000b).

Mild hypothermia represents one possible therapeutic approach to prevent ischemia-reperfusion injury. Two randomized trials and their meta-analyses have demonstrated clear evidence supporting improved outcomes in cardiac arrest survivors treated with mild hypothermia (Bernard et al. 2002, Padosch et al. 2002, Holzer et al. 2005). The fact that hypothermia favorably influences not only a single factor, but rather a variety of simultaneously functioning pathogenic processes, should be considered in the explanation of its beneficial effects.

Several experimental models have demonstrated that hypothermia inhibits the production of free radicals, decreases lipid peroxidation, and protects nuclear DNA from damage and fragmentation caused by reactive oxygen and nitrogen species (Han et al. 2002, Karabiyikoglu et al. 2003, Scumpia et al. 2004, Stefanutti et al. 2005, Jiang et al. 2009). To date, there is only limited evidence regarding the effect of hypothermia on OS in clinical settings, and studies focusing on OS in adult cardiac arrest survivors are lacking. To explore the hypothesis that hypothermia attenuates OS in cardiac arrest survivors, we designed a pilot study to investigate the extent of OS and nitric oxide (NO) production after cardiac arrest. The objective of our study was, therefore, to assess nitrotyrosine and nitrate/nitrite levels in cardiac arrest survivors treated with mild endovascular hypothermia.

The study was performed in accordance with the Declaration of Helsinki and the study protocol was approved by the Institutional Ethics Committee of the $\mathrm{Na}$ Homolce Hospital, Prague, Czech Republic. Surviving patients with favorable neurological outcomes, and family members of deceased subjects or those with unfavorable neurological outcomes provided written informed consent retrospectively. Blood samples drawn from patients who were not willing to participate in the trial (expressed by family members of deceased subjects or those with unfavorable neurological outcomes), were discarded and the clinical data were not used in the analysis.

Patients who experienced cardiac arrest out of hospital, with indications for mild therapeutic hypothermia, were eligible to participate in the present study. Induction of hypothermia was initiated in the ambulance before hospital admission by infusion of icecold saline at a rate of $30 \mathrm{ml} / \mathrm{kg} / \mathrm{h}$. Infusion continued after admission and was discontinued when the core temperature reached $34{ }^{\circ} \mathrm{C}$. An endovascular cooling method was used in all patients (Thermogard XP, Alsius, USA). A triple-lumen cooling catheter (Icy catheter, Alsius, USA) was introduced into the femoral vein, and a catheter equipped with a temperature sensor was placed into the bladder within 30 minutes of admission. A target temperature of $33{ }^{\circ} \mathrm{C}$ was set on the Thermogard XP console and maintained for 24 hours. A rewarming rate of $0.15^{\circ} \mathrm{C}$ per hour was used in all patients, with a final target temperature of $36.8^{\circ} \mathrm{C}$; normothermia was subsequently maintained until awakening.

Blood samples for the measurement of nitrotyrosine and nitrate/nitrite levels were drawn at admission and every 6 hours thereafter for a total of 54 hours. The serum was immediately separated by centrifugation at $1500 \mathrm{rpm}$ for five minutes and aliquots were stored at $-70{ }^{\circ} \mathrm{C}$ until measurement. 3-nitrotyrosine (nitrotyrosine) is a marker of peroxynitrite production; peroxynitrite results from the reaction of $\mathrm{NO}$ and superoxide (Beckman 1996). Nitrotyrosine levels were assessed with a standard ELISA method using monoclonal antibodies stocked in the hospital laboratory, the details of which are described elsewhere (Fisarkova $e t$ al. 2004). Nitrates/nitrites are indirect markers of NO production and have been measured in blood serum (Sun et al. 2010) using a Sievers chemiluminiscent nitric oxide analyzer (GE Analytical Instruments, USA).

Data were analyzed using a repeated-measures ANOVA test with Newman-Keuls multiple comparisons post-test. $\quad \mathrm{P}<0.05$ values were considered to be statistically significant. Values are expressed as mean \pm S.E.M.

Fourteen patients were eligible to participate in the study during the enrollment period. One patient was excluded due to technical problems with blood-sample handling; two patients were excluded because written informed consents could not be obtained; therefore, 11 patients (mean age 58 years) were included in the 
study, the majority of whom (10 of 11) were male. The mean \pm S.E.M. core temperature at admission was $34.9 \pm 0.2{ }^{\circ} \mathrm{C}$ (baseline patient characteristics are summarized in Table 1) and all patients reached the target temperature within one hour of admission. Mean arterial blood pressure in all participants was maintained with norepinephrine and dobutamin, with a goal of $65 \mathrm{~mm} \mathrm{Hg}$ to $90 \mathrm{~mm} \mathrm{Hg}$, none of them needed circulatory support device. All patients who experienced acute myocardial infarction underwent direct percutaneous coronary intervention.

Table 1. Patient characteristics.

\begin{tabular}{|c|c|c|c|c|c|c|}
\hline Patient & $\begin{array}{c}\text { First rhythm } \\
\text { recorded }\end{array}$ & $\begin{array}{c}\text { Structural } \\
\text { heart disease }\end{array}$ & $\begin{array}{c}\text { ROSC } \\
\text { (min) }\end{array}$ & $\begin{array}{c}\text { LVEF } \\
(\%)\end{array}$ & $\begin{array}{c}\text { Alive } \\
\text { (30 days) }\end{array}$ & $\begin{array}{c}\text { CPC } \\
\text { (30 days) }\end{array}$ \\
\hline \multirow[t]{2}{*}{1} & Asystole & AMI & 8 & 20 & Yes & 1 \\
\hline & VFib & AMI & 15 & 40 & Yes & 3 \\
\hline 3 & VFib & AMI & 17 & 50 & Yes & 4 \\
\hline 4 & VFib & Chronic CHD & 12 & 40 & Yes & 1 \\
\hline 5 & VFib & AMI & 16 & 15 & Yes & 1 \\
\hline 6 & VFib & Dilated CMP & 25 & 15 & No & \\
\hline 7 & VFib & AMI & 18 & 35 & Yes & 1 \\
\hline 8 & Asystole & None & 15 & 55 & Yes & 1 \\
\hline 9 & Asystole & AoS & 16 & 30 & Yes & 2 \\
\hline 10 & VFib & Chronic CHD & 45 & 15 & No & \\
\hline 11 & VFib & None & 8 & 50 & Yes & 1 \\
\hline
\end{tabular}

ROSC, return of spontaneous circulation; LVEF, left ventricular ejection fraction measured within one hour of admission; CPC, cerebral performance category; CPC 1, conscious and alert with normal function or only slight disability; CPC 2, conscious and alert with moderate disability; CPC 3, conscious with severe disability; CPC 4, comatose or in a persistent vegetative state; CPC 5, certifiably brain dead or dead by traditional criteria; VFib, ventricular fibrillation; AMI, acute myocardial infarction; CHD, coronary heart disease; CMP, cardiomyopathy; AoS, aortic stenosis.

\section{A. Nitrotyrosine}

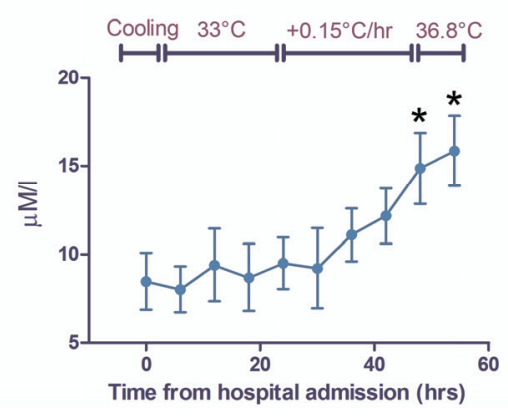

\section{B. Nitrates/Nitrites}

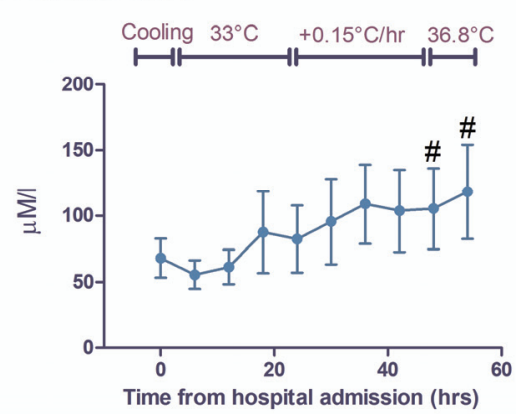

Fig. 1. Levels of nitrotyrosine (Panel A) and nitrates/nitrites (Panel B) in cardiac arrest survivors treated with endovascular hypothermia. Patients were maintained at a core temperature of $33^{\circ} \mathrm{C}$ for 24 hours. Rewarming was subsequently performed at a rate of $0.15^{\circ} \mathrm{C}$ per hour with a target temperature of $36.8^{\circ} \mathrm{C}$; normothermia was controlled until awakening. Values are expressed as mean \pm S.E.M. $* \mathrm{P}<0.05$ for comparisons with values at $0,6,12,18$, and 24 hours; \# $\mathrm{P}<0.05$ for comparisons with values at 6 and 12 hours.
Highly significant differences in nitrotyrosine levels $(\mathrm{P}<0.001)$ were found: nitrotyrosine levels during the normothermic period (48 and 54 hours) were significantly higher $(\mathrm{P}<0.05)$ compared with nitrotyrosine levels in samples drawn during the hypothermic period (0, 6, 12, 18, and 24 hours) (Fig. 1A). Significant differences were observed in nitrate/nitrite levels $(\mathrm{P}<0.05)$ : the values in samples obtained at normal core temperature (48 and 54 hours) were significantly higher than the values obtained during early hypothermia (6 and
12 hours) $(\mathrm{P}<0.05)$ (Fig. 1B).

The major finding of our study was the reduction in nitrotyrosine and nitrate/nitrite levels during mild therapeutic hypothermia compared with the normothermic period in cardiac arrest survivors. It has been reported that OS plays an important role in the pathogenesis of ischemia-reperfusion injury (Dhalla et al. 2000a), and a rapid rise in markers of OS and NO production can be detected in various acute clinical situations such as trauma, stroke, liver failure or 
infection (Hayashi et al. 1999, Jiang et al. 2009). Mild hypothermia was introduced as a therapy for ischemiareperfusion injury in cardiac arrest survivors after publication of clinical trials proving its effectiveness in improving clinical outcomes (Bernard et al. 2002, HACA-Study-Group 2002). Results of the present study have, for the first-time, shown that hypothermia may attenuate OS in these patients, which can at least partly explain its beneficial effect.

Suppression of OS and NO production using hypothermia has previously been described in animal models. Our results are consistent with several other previously published experimental observations. Jiang et al. (2009) described normalization of nitrate/nitrite levels and significant attenuation of NO synthase expression in the brain using hypothermia in a rat model of acute ischemic liver failure. Stefanutti et al. (2005) observed that hypothermia suppressed OS in a rat model of intestinal ischemia-reperfusion injury. Inhibition of NO production and myeloperoxidase-mediated damage in the hearts of endotoxemic rats was reported by Scumpia et al. (2004). Han et al. (2002) found that hypothermia inhibited NO generation in experimental models of stroke and inflammation. Hypothermia-induced attenuation of NO synthase isoform expression was described by Karabiyikoglu et al. (2003) after focal cerebral ischemia in rats. Finally, Lei et al. (1994) observed decreased lipid peroxidation and preserved antioxidant defenses as a result of hypothermia in a canine model of resuscitated cardiac arrest.

Supportive clinical evidence of the effect of hypothermia on OS remains insufficient. Our observations are consistent with those of Hayashi et al. (1999), who described decreased nitrate/nitrite levels as a result of cerebral cooling to $32{ }^{\circ} \mathrm{C}$ to $33{ }^{\circ} \mathrm{C}$ in patients who experienced head injury and intracerebral hemorrhage. Similarly, Wenisch et al. (1996) observed a reduction in reactive oxygen species production when mild hypothermia was induced during surgery. Recently, Bayir et al. (2009) published a well-designed study demonstrating the preservation of antioxidant defenses after initiation of therapeutic hypothermia following severe brain injury in infants and children.

Our study has several limitations, including the small number of patients enrolled and, especially, the absence of a control group. We believe, however, that it would have been unethical to arrange for a control group either by delaying the induction of hypothermia or maintaining a temperature other than the recommended temperature of $33{ }^{\circ} \mathrm{C}$ during hypothermia. It can be speculated that the ischemia-reperfusion reaction that occurs after cardiac arrest, if not mitigated by hypothermia, induces an increase in OS burden comparable with the OS burden previously reported for infection, stroke or trauma (Hayashi et al. 1999, Jiang et al. 2009). OS and NO production can also be influenced by an imbalance in ionic (e.g, potassium or calcium) homeostasis and lactate acidosis. As per current clinical practice, however, these disturbances were stabilized in all patients during the early hours after admission, likely removing the possibility of significant variations in ionic homeostasis and lactate acidosis. Furthermore, it is unlikely that variations in core temperature would have influenced the levels of the analyzed parameters because the endovascular hypothermia system enables the maintenance of a stable core temperature at a predetermined target value.

In conclusion, our study describes the reduction of OS and NO production during therapeutic endovascular hypothermia in cardiac arrest survivors and, therefore, provides indirect evidence that hypothermia may influence OS and NO production in these patients. It can be hypothesized that attenuation of OS and $\mathrm{NO}$ production is at least partially responsible for the beneficial effect of hypothermia in the clinical outcomes of cardiac arrest survivors.

\section{Conflict of Interest}

There is no conflict of interest.

\section{Acknowledgements}

This study was supported by a grant from the Czech Ministry of Health, Nr. NT12153.

\section{References}

BAYIR H, ADELSON PD, WISNIEWSKI SR, SHORE P, LAI Y, BROWN D, JANESKO-FELDMAN KL, KAGAN VE, KOCHANEK PM: Therapeutic hypothermia preserves antioxidant defenses after severe traumatic brain injury in infants and children. Crit Care Med 37: 689-695, 2009.

BECKMAN JS: Oxidative damage and tyrosine nitration from peroxynitrite. Chem Res Toxicol 9: 836-844, 1996. 
BERNARD SA, GRAY TW, BUIST MD, JONES BM, SILVESTER W, GUTTERIDGE G, SMITH K: Treatment of comatose survivors of out-of-hospital cardiac arrest with induced hypothermia. N Engl J Med 346: 557-563, 2002.

DHALLA NS, ELMOSELHI AB, HATA T, MAKINO N: Status of myocardial antioxidants in ischemia-reperfusion injury. Cardiovasc Res 47: 446-456, 2000a.

DHALLA NS, TEMSAH RM, NETTICADAN T: Role of oxidative stress in cardiovascular diseases. J Hypertens 18 : 655-673, 2000b.

FISARKOVA B, VYTASEK R, MIKOVA D, VIZEK M: Hyperoxia attenuated nitrotyrosine concentration in the lung tissue of rats with experimental pneumonia. Physiol Res 53: 487-492, 2004.

HACA-STUDY-GROUP: Mild therapeutic hypothermia to improve the neurologic outcome after cardiac arrest. $N$ Engl $J$ Med 346: 549-556, 2002.

HAN HS, QIAO Y, KARABIYIKOGLU M, GIFFARD RG, YENARI MA: Influence of mild hypothermia on inducible nitric oxide synthase expression and reactive nitrogen production in experimental stroke and inflammation. $J$ Neurosci 22: 3921-3928, 2002.

HAYASHI N, UTAGAWA A, KINOSHITA K, IZUMI T: Application of a novel technique for clinical evaluation of nitric oxide-induced free radical reactions in ICU patients. Cell Mol Neurobiol 19: 3-17, 1999.

HOLZER M, BERNARD SA, HACHIMI-IDRISSI S, ROINE RO, STERZ F, MULLNER M: Hypothermia for neuroprotection after cardiac arrest: systematic review and individual patient data meta-analysis. Crit Care Med 33: 414-418, 2005.

JIANG W, DESJARDINS P, BUTTERWORTH RF: Hypothermia attenuates oxidative/nitrosative stress, encephalopathy and brain edema in acute (ischemic) liver failure. Neurochem Int 55: 124-128, 2009.

KARABIYIKOGLU M, HAN HS, YENARI MA, STEINBERG GK: Attenuation of nitric oxide synthase isoform expression by mild hypothermia after focal cerebral ischemia: variations depending on timing of cooling. J Neurosurg 98: 1271-1276, 2003.

LEI B, TAN X, CAI H, XU Q, GUO Q: Effect of moderate hypothermia on lipid peroxidation in canine brain tissue after cardiac arrest and resuscitation. Stroke 25: 147-152, 1994.

NEUMAR RW, NOLAN JP, ADRIE C, AIBIKI M, BERG RA, BOTTIGER BW, CALLAWAY C, CLARK RS, GEOCADIN RG, JAUCH EC, KERN KB, LAURENT I, LONGSTRETH WT JR, MERCHANT RM, MORLEY P, MORRISON LJ, NADKARNI V, PEBERDY MA, RIVERS EP, RODRIGUEZ-NUNEZ A, SELLKE FW, SPAULDING C, SUNDE K, VANDEN HOEK T: Post-cardiac arrest syndrome: epidemiology, pathophysiology, treatment, and prognostication. A consensus statement from the International Liaison Committee on Resuscitation (American Heart Association, Australian and New Zealand Council on Resuscitation, European Resuscitation Council, Heart and Stroke Foundation of Canada, InterAmerican Heart Foundation, Resuscitation Council of Asia, and the Resuscitation Council of Southern Africa); the American Heart Association Emergency Cardiovascular Care Committee; the Council on Cardiovascular Surgery and Anesthesia; the Council on Cardiopulmonary, Perioperative, and Critical Care; the Council on Clinical Cardiology; and the Stroke Council. Circulation 118: 2452-2483, 2008.

NOLAN JP, NEUMAR RW, ADRIE C, AIBIKI M, BERG RA, BOTTIGER BW, CALLAWAY C, CLARK RS, GEOCADIN RG, JAUCH EC, KERN KB, LAURENT I, LONGSTRETH WT, MERCHANT RM, MORLEY P, MORRISON LJ, NADKARNI V, PEBERDY MA, RIVERS EP, RODRIGUEZ-NUNEZ A, SELLKE FW, SPAULDING C, SUNDE K, HOEK TV: Post-cardiac arrest syndrome: epidemiology, pathophysiology, treatment, and prognostication. A Scientific Statement from the International Liaison Committee on Resuscitation; the American Heart Association Emergency Cardiovascular Care Committee; the Council on Cardiovascular Surgery and Anesthesia; the Council on Cardiopulmonary, Perioperative, and Critical Care; the Council on Clinical Cardiology; the Council on Stroke. Resuscitation 79: 350-379, 2008.

PADOSCH SA, KERN KB, BOTTIGER BW: Therapeutic hypothermia after cardiac arrest. N Engl J Med 347: 63-65, author reply 63-65, 2002.

SCUMPIA PO, SARCIA PJ, KELLY KM, DEMARCO VG, SKIMMING JW: Hypothermia induces anti-inflammatory cytokines and inhibits nitric oxide and myeloperoxidase-mediated damage in the hearts of endotoxemic rats. Chest 125: 1483-1491, 2004. 
STEFANUTTI G, PIERRO A, VINARDI S, SPITZ L, EATON S: Moderate hypothermia protects against systemic oxidative stress in a rat model of intestinal ischemia and reperfusion injury. Shock 24: 159-164, 2005.

SUN Y, ZHU Z, LANGNAS AN, GRANT WJ, BOTHA JF, ZHAO Y, SUDAN DL, MERCER DF: Plasma nitrite and nitrate levels as a noninvasive marker of pathology after human small bowel transplantation. Transplantation 89: 307-311, 2010.

WENISCH C, NARZT E, SESSLER DI, PARSCHALK B, LENHARDT R, KURZ A, GRANINGER W: Mild intraoperative hypothermia reduces production of reactive oxygen intermediates by polymorphonuclear leukocytes. Anesth Analg 82: 810-816, 1996. 